\title{
The question of Sudan: a hydro-economic optimization model for the Sudanese Blue Nile
}

\author{
S. Satti ${ }^{1}$, B. Zaitchik ${ }^{1}$, and S. Siddiqui ${ }^{2}$ \\ ${ }^{1}$ Department of Earth and Planetary Sciences, Johns Hopkins University, Baltimore, MD 21218, USA \\ ${ }^{2}$ Departments of Civil Engineering and Applied Mathematics \& Statistics, Johns Hopkins Systems Institute, \\ Johns Hopkins University, Baltimore, MD 21218, USA \\ Correspondence to: S. Satti (ssatti1@jhu.edu)
}

Received: 4 September 2014 - Published in Hydrol. Earth Syst. Sci. Discuss.: 21 October 2014

Revised: 9 March 2015 - Accepted: 26 March 2015 - Published: 13 May 2015

\begin{abstract}
The effects of development and the uncertainty of a changing climate in eastern Africa pose myriad challenges for water managers along the Blue Nile. Sudan's large irrigation potential, hydroelectric dams, and prime location within the basin mean that Sudan's water management decisions will have great social, economic and political implications for the region. At the same time, Sudan's water use options are constrained by tradeoffs between upstream irrigation developments and downstream hydropower facilities as well as by the country's commitments under existing or future transboundary water sharing agreements. Here, we present a model that can be applied to evaluate optimal allocation of surface water resources to irrigation and hydropower in the Sudanese portion of the Blue Nile. Hydrologic inputs are combined with agronomic and economic inputs to formulate an optimization model within the General Algebraic Modeling System (GAMS). A sensitivity analysis is performed by testing model response to a range of economic conditions and to changes in the volume and timing of hydrologic flows. Results indicate that changing hydroclimate inputs have the capacity to greatly influence the productivity of Sudan's water resource infrastructure. Results also show that the economically optimal volume of water consumption, and thus the importance of existing treaty constraints, is sensitive to the perceived value of agriculture relative to electricity as well as to changing hydrological conditions.
\end{abstract}

\section{Introduction}

The Nile basin spans parts of 11 different countries in one of the most underdeveloped regions in the world. The transboundary nature of the Nile presents water-sharing challenges between upstream and downstream riparian nations (Waterbury et al., 1998). This is particularly true in the eastern Nile basin, which is typically defined as the tributaries that arise in the Ethiopian Highlands - primarily the Blue Nile, Tekeze-Atbara, and Baro-Akobo-Sobat - together with the main stem Nile north of Khartoum (Fig. 1). The eastern Nile tributaries collectively contribute over $80 \%$ of flow in the main stem Nile. The eastern Nile basin also exhibits strong hydrological connectivity, in that upstream climate variability and development directly impact downstream resources in a manner that is not observed in the White Nile system, where lakes and wetlands serve as a buffer between the Equatorial Lakes headwaters region and downstream water deficit areas in Sudan and Egypt (Blackmore and Whittington, 2008). For this reason, the utilization of eastern Nile waters has long been a source of transboundary tension, most notably between Egypt, which claims historical rights to the majority of Nile River water, and Ethiopia, which has a strong interest in developing the eastern Nile tributaries for hydropower and other uses.

While the diplomatic tensions between Egypt and Ethiopia have dominated the political and media discourse on eastern Nile basin development (Cascao, 2008; Igunza, 2014; Hussein, 2014; Gebreluel, 2014), Sudan has the greatest potential to influence transboundary distribution of water resources. The 1959 Nile Waters Agreement grants Sudan the right to use 18.5 billion $\mathrm{m}^{3}$ of Nile water per year. At 


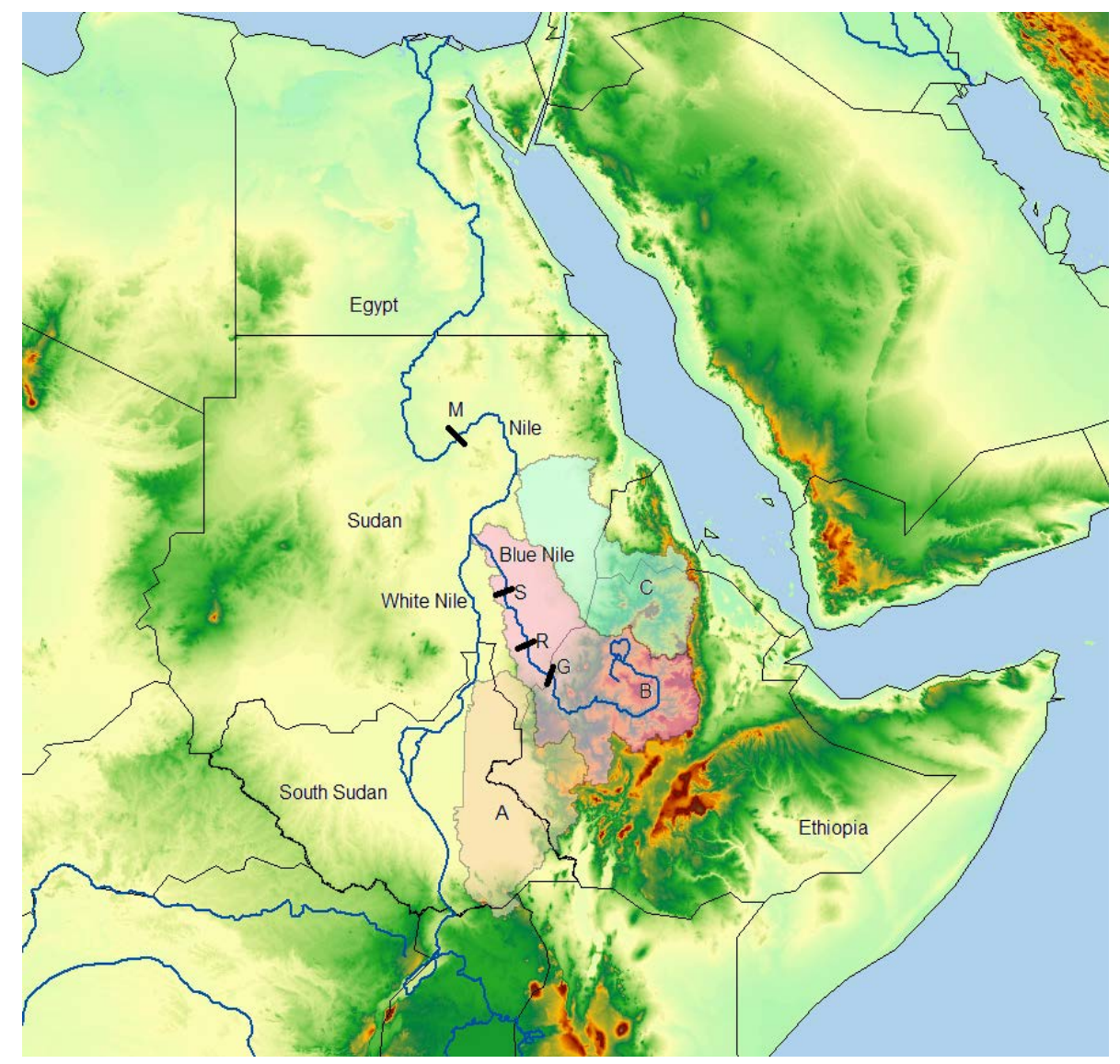

Figure 1. Map of the Nile and its tributaries: $A=$ Baro-Akobo-Sobat, $B=$ Blue Nile, $C=$ Tekese-Atbara basins, $S=$ Sennar Dam, $\mathrm{R}=$ Roseries Dam, $\mathrm{M}=$ Merowe Dam, and $\mathrm{G}=\mathrm{GERD}$.

present, however, Sudan uses less than this allocation; its actual water demand has been estimated to be approximately 16.1 billion $\mathrm{m}^{3} \mathrm{yr}^{-1}$ (Jeuland, 2010). This value could change in the future, both through internal development decisions and through external influences such as climate change and upstream infrastructure in Ethiopia. Where climate change has the potential to alter the magnitude of Blue Nile inflow and local evaporative demand, upstream infrastructure would be expected to regularize the timing of flows and to reduce silt load entering Sudan. Silt accumulates over time in the reservoir and reduces the volume of the reservoir. This affects hydropower production, reduces the available water for irrigation, imposes dredging costs, and reduces flood control capabilities.

In this context, there is a need for analytical tools focused on Sudan's hydro-development options. In particular, it is important to understand how impending changes affecting the Sudanese portion of the eastern Nile basin, including climate change and upstream development in Ethiopia, are likely to affect Sudan's use of its Nile River resources for hydropower and irrigation. The objective of this paper is to present an optimization model that illustrates the sensitivities of Sudan's
Blue Nile and main stem Nile water resource infrastructure to changes in climate and upstream development.

\subsection{The Blue Nile in Sudan}

Approximately 60 billion $\mathrm{m}^{3}$ of water flow annually from the Blue Nile basin in Ethiopia to Sudan. Interseasonal variability is large, with flows peaking in August and September, and interannual variability is also considerable - gauged flow at Roseries (Fig. 1) has an interannual variability equal to $25 \%$ of the mean flow. The basin is also undergoing climate change that has had a significant impact on temperature but, as of yet, no clear directional impact on total annual precipitation or river discharge. In coming decades, climate change impacts on basin hydrology are expected to become more significant.

The magnitude, seasonality, and even directionality of this change, however, are highly uncertain. Global climate models (GCMs) participating in the 5th Coupled Model Intercomparison Project (CMIP5; Taylor, 2012) exhibit no consensus on projected change. A recent study of 10 CMIP5 models revealed that projected precipitation change in the Blue Nile headwaters ranged from an increase of almost 
$40 \%$ by the mid-twenty-first century relative to the late twentieth century to a decrease of approximately $40 \%$ in the same time period (Bhattacharjee and Zaitchik, 2015). Interestingly, some of the models with the most widely diverging projections demonstrate reasonably good representation of current climate patterns and variability for commonly used model evaluation metrics (Bhattacharjee and Zaitchik, 2015). This range of uncertainty is evident in previous multimodel comparison studies as well, as past analyses have found twentyfirst century change in Upper Blue Nile basin flows ranging from 133 to $-35 \%$ and precipitation ranging from 55 to $-9 \%$ (Yates and Strzepek, 1998). Other studies of selected GCMs have found a smaller range of uncertainty, but no consensus on direction of change: Elshamy et al. (2008) examined 17 selected GCMs for the period 2081-2098 and found flow changes ranging from -15 to $14 \%$, while Nawaz et al. (2010) analyzed the output of three GCMs and deduced that the mean annual Blue Nile runoff would change by +15 , 1 or $-9 \%$ by the year 2025 . Analysis conducted by Taye et al. (2010) projected future climate scenarios and ran them through two hydrologic models for two catchments representing source regions of the Blue and White Nile. Results illustrated a large range in the projected flows from the baseline for both basins. Changes in projected mean annual flows from the Blue Nile catchment range from approximately -80 to $70 \%$.

In addition to climate change, proposed infrastructure projects will drastically alter the nature of downstream flows. There are currently no large structures along the main stem of the Blue Nile in Ethiopia, but the western portion of Ethiopia holds tremendous hydroelectric potential (Guariso et al., 1987). The Ethiopian government has had plans to increase utilization of this energy source since at least 50 years ago, when the concept of a cascade of hydroelectric dams on the Blue Nile was first proposed (Bureau of Reclamation, 1964; Guariso et al., 1987). The concept of a cascade of dams is still of interest to Ethiopia, but at present the country's development energies are focused on construction of the Grand Ethiopian Renaissance Dam (GERD), located at the border with Sudan (Fig. 1). The GERD will be the largest dam in Africa, holding back more than 60 billion $\mathrm{m}^{3}$ of water, and is expected to generate more than $5000 \mathrm{MW}$ of electricity (Hammond, 2013). The construction of this dam will affect many aspects of water sharing in the region and raises numerous questions about its effects on downstream riparian nations.

Sudan has one large dam on the main stem Nile - the $1250 \mathrm{MW}$ capacity, $67 \mathrm{~m}$ high Merowe Dam, located $800 \mathrm{~km}$ north of Khartoum near the fourth cataracts (Teodoru, 2006). In addition to Merowe, Sudan has two large dams along the Blue Nile reach, at Roseires and Sennar. Roseries was constructed in 1966 (Chesworth et al., 1990) with a capacity to generate $280 \mathrm{MW}$ of electricity. Recent construction heightened the dam and increased the reservoir volume from 3.3 to more than 7 billion $\mathrm{m}^{3}$ (McCartney et al., 2009).
The Sennar Dam was constructed in 1925 and holds back 900 million $\mathrm{m}^{3}$ of water (McCartney et al., 2009). Both dams were constructed to regulate flows that feed into multiple irrigation schemes; among them is the 800000 hectare (ha) Geziera scheme. The Geziera was constructed by the governing British magistrate in 1925 as the largest single irrigation scheme in the world at the time (Bernal, 1997). The dams also supply various schemes in Rahad and Suki as well as upstream and downstream of Sennar (McCartney et al., 2009). The Merowe Dam (Fig. 1) is located further downstream, in the cataracts of the main stem Nile in northern Sudan. This is a highly arid area and the dam's primary purpose is hydropower rather than irrigation. It was constructed in 2009 and now supplies the majority of Sudan's hydroelectric power.

All discussions of Nile flow and water resource development take place against the background of a complex and lengthy history of colonial and post-colonial era negotiations (Swain, 1997). The most recent legally binding treaty involving Sudan is the 1959 Nile Waters Agreement, under which Sudan and Egypt agreed to divide the average flow of 84 billion $\mathrm{m}^{3}$ at the old Aswan Dam between the two countries: 55.5 billion $\mathrm{m}^{3}$ to Egypt, 10 billion $\mathrm{m}^{3}$ to evaporation losses, and 18.5 billion $\mathrm{m}^{3}$ to Sudan. The treaty also granted Sudan permission to build a dam at Roseries. The agreement was limited to the two downstream nations and does not include any upstream riparian countries, and for this reason it is generally not recognized by the other countries on the Nile.

\subsection{Hydro-economic modeling in the Nile basin}

Hydro-economic models integrate natural hydrologic dynamics, infrastructure, and management options into a framework of economic costs and benefits. They are particularly valued in complex water management problems because they provide a dynamic analysis of water resources and needs that guides basin managers and stakeholders towards an economically optimal management strategy in place of traditional, static systems based on water rights and fixed allocations (Harou et al., 2009). The core structure of most river basin hydro-economic models is roughly similar: flows pass through a network of rivers and canals (or aquifers) and encounter nodes that represent resource infrastructure, such as reservoirs, abstraction sites, hydroelectric facilities, etc. But, there is considerable diversity in the conceptual approach (simulation vs. optimization), representation of time (deterministic, stochastic, or dynamic), the manner in which submodels are integrated into the hydro-economic solution (modular vs. holistic), and, for optimization models, in the optimization objective function and algorithm (Harou et al., 2009).

Not surprisingly, the Nile River basin has been a common and important target for hydro-economic analyses. One relatively early effort was reported in Guariso et al. (1987), in which a linear optimization model was implemented to eval- 
uate the effect of the long-discussed cascade of hydroelectric dams on the Ethiopian Blue Nile on overall benefit and on water economics in Sudan and Egypt. The optimization objectives of this model were to maximize hydropower production in Egypt, Sudan and Ethiopia, as well as downstream agricultural water supply. Simulations indicated that there was minimal tradeoff between the two competing objectives. Thus, Ethiopia's increased hydropower output would have a minor adverse effect on downstream riparian nations, but upstream flow regulation also had benefits for downstream riparian nations, including the fact that an increase in upstream flow regulation would decrease water levels in the highly evaporative downstream reservoirs, thus increasing total water availability for downstream riparian nations. This finding has been confirmed by subsequent modeling studies (e.g., Blackmore and Whittington, 2008) and plays a role in studies that investigate the benefits of cooperation in the basin (Whittington, 2004).

Another influential and relatively early optimization model for the Nile is the Nile Decision Support Tool (DST), which was developed by the Georgia Water Resources Institute. This model performs a basin-wide hydrological and hydraulic simulation along with reservoir optimization capabilities and scenario assessment (Yao and Gerogakakos, 2003; Georgakakos, 2007). The optimization model in DST utilizes the extended linear quadratic Gaussian (ELQG) control method in order to perform a stochastic multi-criteria optimization that aims to find the optimal reservoir operation (Georgakakos, 1987, 1989).

A more recent basin-wide hydro-economic optimization model, the Nile Economic Optimization Model (NEOM), was presented by Whittington et al. (2005) using GAMS software. This model was used to assess the economic implications of various infrastructural developments within the basin and aims to maximize for basin-wide economic benefits due to irrigation and hydropower production. The authors quantify the economic benefit of cooperation by comparing the total benefits calculated from current allocation with the total benefits derived from full communication and cooperation between various riparian nation states. They found that cumulative economic benefits for all players more than doubled the realized total benefit from USD 4.1 billion in the status quo scenario to more than USD 9 billion when all nations were fully cooperating.

Other recent modeling efforts have focused on a subset of the basin and investigated problems of dynamic and transient system management. In the eastern Nile, Goor et al. (2010) present a dynamic reservoir optimization model that employs a stochastic dual dynamic optimization program (SDDP). The model identifies the most economically efficient policies for large-scale reservoirs (Goor et al., 2010). Block and Strzepek (2010) focus on the Ethiopian Blue Nile, implementing the Investment Model for Planning Ethiopian Nile Development (IMPEND) that calculates the economic benefit of proposed development under changing climatic condi- tions. IMPEND has the ability to model the transient filling stages of the dams, as well as the stochastic nature of the climate variables, allowing for a focus on the transient nature of the development process, an aspect of water management that is absent from most other hydro-economic models of the basin. Block and Strzepek $(2010,2012)$ apply the model to climate change analysis and find that the omission of this transient period in models results in the overestimation of total net benefits by more than USD 6 billion, as well as a significant change in the benefit-to-cost ratio of the project. Block and Strzepek (2010) also highlight changes in the hydrology that are neglected in models with no filling process: reservoir filling scenarios require that up to $170 \%$ more water be retained in Ethiopia over 30 years compared to scenarios where the reservoirs are assumed to already be filled.

More recently, Jeuland (2010) and Jeuland and Whittington (2014) present hydro-economic simulations that analyze decision making within the Nile basin under a changing climate. Jeuland (2010) presents a basin-wide hydro-economic framework that integrates a stochastic flow generator, a hydrological simulation model and an economic model for the Nile. His analysis shows that varying specific economic and physical parameters combine to have a substantial impact on net present value. Jeuland and Whittington (2014) present long term planning hydropower investment options within Ethiopia under varying hydrological conditions. By using simulations, the authors are able to develop performance metrics for the different options, and show that results are dependent on the decision makers' risk preference.

The Sudan Hydro-economic Optimization Model (SHOM) presented in this paper is intended to provide a complementary perspective on optimal water resource decision making in the eastern Nile. In contrast to earlier modeling efforts, we focus specifically on the Sudanese portion of the Blue Nile and the main stem Nile north of Khartoum. We do this because Sudan is a relatively understudied and pivotal player in Nile water resource management. In addition, we use a nonlinear optimization model (see Sect. 2) that maximizes economic benefits and assesses tradeoffs between hydropower production and irrigation within Sudan.

\section{Methods}

\subsection{The SHOM optimization model}

The General Algebraic Modeling System (GAMS) is frontend software that can be used to solve nonlinear multiobjective optimization problems by calling various solvers. By using the reduced gradient method in the CONOPT solver, the model seeks a stationary point while reducing the number of variables by conducting a variable selection process. By curtailing the number of variables and linearizing the nonlinear constraints via a Taylor series approximation, 


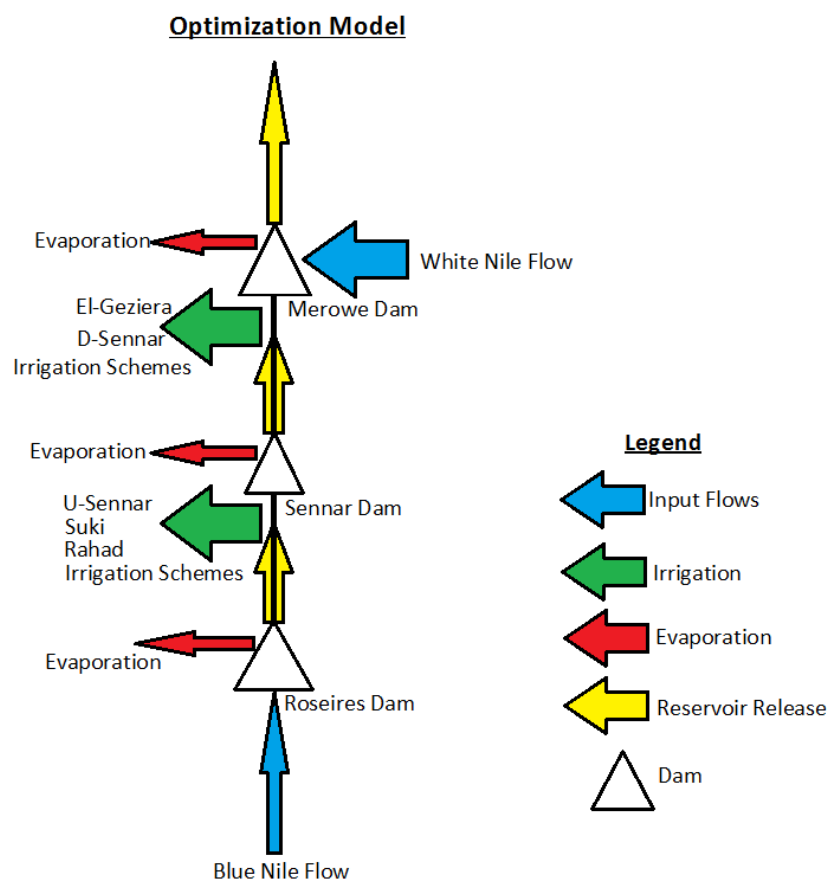

Figure 2. Schematic of the optimization model.

the algorithm simplifies the problem and solves for the nonlinear objective (Drud, 1992).

SHOM runs in monthly time steps. In this implementation, the simulation network includes two dams located on the Blue Nile reach (Roseires and Sennar), and one dam on the main stem Nile (Merowe); agriculture is represented by five irrigation schemes corresponding to existing developments along the Blue Nile (Fig. 2). The combined storage volume of all dams is approximately 20 billion $\mathrm{m}^{3}$, and the total irrigable area is 1.4 million ha. Tables 1 and 2 define all the parameters and variables in SHOM.

\subsubsection{Objective function}

The objective function of SHOM consists of two objectives that it seeks to maximize: agricultural and hydropower net benefits. Benefits refer to the total economic value attributed to each respective year summed over the 20 year run period. As noted by Whittington et al. (2005), the meaning of "value" takes more than one form. In this paper, the total net benefit attributed to the economic value of water is defined by the objective function and incorporates the benefits at each site location. Thus, the total value of water is seen from the perspective of the producer (the state) and not from the perspective of the consumer. The objective function, illustrated below (Eq. 1), represents the economic benefits from the agricultural and hydropower sectors. The total benefit attributed to hydropower production assumes infinite demand and is calculated as the total hydropower produced times the price per kilowatt hour. Initial dam infrastructural cost, cost of energy transmission and cost of dredging are not included in the objective function. Furthermore, it is assumed in the sensitivity analysis presented in this paper that the price of electricity is fixed. Thus,

Objective $=\max \sum_{\mathrm{m}, \mathrm{y}}\left(D^{y} \cdot \mathrm{bi}_{\mathrm{m}, \mathrm{y}}+D^{y} \cdot \mathrm{bh}_{\mathrm{m}, \mathrm{y}}\right)$,

where $D^{y}=$ discount rate, $\mathrm{bi}_{\mathrm{m}, \mathrm{y}}$ is the total benefits from irrigation, $b h_{m, y}$ is the total benefits from hydropower, and all variables are dependent on month $(\mathrm{m})$ and year $(\mathrm{y})$.

\subsubsection{Hydropower constraints}

Total hydropower generation $\left(\mathrm{KWH}_{1, \mathrm{~m}, \mathrm{y}}\right)$ is dependent on two variables (Eq. 2), the amount of water passing through the turbines at any given time step ( $\left(\mathrm{rhe}_{1, \mathrm{~m}, \mathrm{y}}\right)$, and the total height of water in the dam that forces water through the turbines $\left(h_{1, \mathrm{~m}, \mathrm{y}}\right)$ (Cohon, 2003; Loucks et al., 1981).

$\forall_{1, \mathrm{~m}, \mathrm{y}}, \mathrm{KWH}_{1, \mathrm{~m}, \mathrm{y}}=c \cdot \mathrm{effh} \cdot n \cdot \mathrm{rhe}_{1, \mathrm{~m}, \mathrm{y}} h_{1, \mathrm{~m}, \mathrm{y}}$

Production of hydropower is constrained by the dam's generation capacity; thus, any additional release is categorized by the model as non-hydropower release. effh is the efficiency of the dams, which was assumed to be 0.85 in the model. There is also a conversion factor $(c) ; c=2.61 \times 10^{-3}$.

As shown in Eq. (3), total hydropower benefits for each month in each year are dependent on the price of hydropower $(P)$ and the sum of hydropower produced at all dam locations (1).

$\mathrm{bh}_{\mathrm{m}, \mathrm{y}}=\sum_{1}\left(P \cdot \mathrm{KWH}_{1, \mathrm{~m}, \mathrm{y}}\right)$

\subsubsection{Irrigation constraints}

The water used for irrigation $\left(i_{1, \mathrm{~m}, \mathrm{y}}\right)$ is dependent on the crop water requirement (i.e., the volume of water needed per unit area of crop cultivated), and the area irrigated during cropping season. Values of crop water requirement (water) were drawn from a World Bank report (Plusquellec, 1990). The area irrigated $\left(\right.$ Area $\left._{c, 1, \mathrm{~m}, \mathrm{y}}\right)$ fluctuates annually but remains constant during the cropping season (Eq. 4). Therefore, the volume of water allocated for irrigation is

$i_{1, \mathrm{~m}, \mathrm{y}}=\sum_{c}\left(\right.$ effi $_{c} \cdot$ Water $\left._{c, 1, \mathrm{~m}, \mathrm{y}} \cdot \operatorname{Area}_{c, 1, \mathrm{~m}, \mathrm{y}}\right)$.

Efficiency of irrigation was assumed to be dependent on the crop type (Table 1; Elamin et al., 2011; NB: the agricultural output in the objective function is irrigation fed; rain-fed agriculture was not considered). Therefore, the total benefit due to irrigation for each $\mathrm{m}$, at each $\mathrm{y}$, is

$\mathrm{bi}_{\mathrm{m}, \mathrm{y}}=\sum_{c, 1}\left(\mathrm{effi}_{c} \cdot v_{\mathrm{c}} \cdot\right.$ Water $\left._{c, 1, \mathrm{~m}, \mathrm{y}} \cdot \operatorname{Area}_{c, 1, \mathrm{~m}, \mathrm{y}}\right)$, 
Table 1. SHOM parameters.

\begin{tabular}{|c|c|c|c|}
\hline Parameters & Value range & Units & Notes \\
\hline Discount rate $(D)$ & $3-7 \%$ & - & $5 \%$ used in the simulation analysis \\
\hline \multicolumn{4}{|l|}{ Flows $(q)$} \\
\hline High & $20 \%$ & \multirow{4}{*}{ Million $\mathrm{m}^{3}$} & \multirow{4}{*}{$\mathrm{CI}=$ confidence intervals } \\
\hline Low & $-20 \%$ & & \\
\hline Smooth & Three month average & & \\
\hline Bootstrapped flows & $5,50,95 \%$ CI & & \\
\hline \multicolumn{4}{|l|}{ Water requirement (Water) } \\
\hline Wheat & $0.23-0.48$ & \multirow{4}{*}{$\mathrm{m}^{3} \mathrm{~m}^{-2}$} & Value depends on month. \\
\hline Cotton & $0.48-0.73$ & & Plusquellec (1990), \\
\hline Sorghum & $0.69-0.94$ & & Ghezae (1998) \\
\hline Groundnuts & $0.89-1.14$ & & \\
\hline \multicolumn{4}{|l|}{ Efficiency } \\
\hline Effh & 0.85 & - & Hydropower efficiency \\
\hline Irrigation & & & Irrigation efficiency \\
\hline Wheat & 0.233 & - & \\
\hline Cotton & 0.065 & - & \\
\hline Sorghum & 0.333 & - & \\
\hline Groundnuts & 0.312 & - & \\
\hline Power $(P)$ & 0.08 & cents $\mathrm{Kwh}^{-1}$ & \\
\hline Evaporation & $0.08-0.3$ & $\mathrm{~m}^{3} \mathrm{~m}^{-2}$ & $\begin{array}{l}\text { Evaporation is derived from } \\
\text { the Thornthwaite equation } \\
\text { (Thornthwaite, 1948). Range } \\
\text { depends on month and location. }\end{array}$ \\
\hline$e$ & $1.9-76.5$ & Million $\mathrm{m}^{3}$ & $e=\mathrm{Ev} \cdot$ Dam Surface Area \\
\hline
\end{tabular}

Table 2. SHOM variable definitions.

\begin{tabular}{|c|c|c|c|}
\hline Variables & Definition & Units & Notes \\
\hline$s$ & Storage & Million $\mathrm{m}^{3}$ & $\begin{array}{l}\text { Storage volume is assumed to be } \\
\text { cylindrical in the model. }\end{array}$ \\
\hline$r$ & Release $(r=$ rhe + nhe $)$ & Million $\mathrm{m}^{3}$ & $\begin{array}{l}\text { Release has two components: } \\
\text { rhe = hydropower release, } \\
\text { nhe = non-hydropower release }\end{array}$ \\
\hline$i$ & Irrigation volume & Million $\mathrm{m}^{3}$ & \\
\hline Area & Area irrigated & Million $\mathrm{m}^{2}$ & \\
\hline bi & Irrigation benefits & $\$$ & \\
\hline KWH & Power generated & $\mathrm{kWh}$ & $\begin{array}{l}\text { Calculated from the hydropower } \\
\text { equation. Function of hydropower } \\
\text { release and head. }\end{array}$ \\
\hline bh & Hydropower benefits & $\$$ & \\
\hline
\end{tabular}

where $v_{\mathrm{c}}$ is the marginal value of water for each crop (see Sect. 2.2.1 for more details.)

Finally, as per the 1959 Nile agreement, Sudan's portion of withdrawals is limited to 18.5 billion $\mathrm{m}^{3}$ of water annually. Since our model is restricted to portions of the Blue Nile, we assume the maximum bounds to be 14.5 billion $\mathrm{m}^{3}$ (Eq. 6). This approximation is based on the relative contribution of Blue Nile flows to the Nile system, and the recognition that the largest irrigation schemes in Sudan are located along the Blue Nile. Thus, for a simulation of $Y$ years, the total water consumed by Sudan should be

$\sum_{1, \mathrm{~m}, \mathrm{y}}\left(i_{1, \mathrm{~m}, \mathrm{y}}\right)+\sum_{1, \mathrm{~m}, \mathrm{y}}\left(e_{1, \mathrm{~m}, \mathrm{y}}\right) \leq Y \cdot 14.5$ billion $\mathrm{m}^{3}$.

A second constraint is included in the model to ensure Egypt's share and to prevent a large intake during drought years by ensuring Egypt's fractional share during those years (Eq. 7):

$\sum_{1, \mathrm{~m}}\left(i_{1, \mathrm{~m}, \mathrm{y}}\right)+\sum_{1, \mathrm{~m}}\left(e_{1, \mathrm{~m}, \mathrm{y}}\right) \leq 0.28 \cdot \sum_{\mathrm{m}}\left(R_{\mathrm{y}}\right)$ 
Table 3. Marginal values of water for each crop.

\begin{tabular}{lrrrrrr}
\hline \multicolumn{7}{c}{ Marginal value of water $\left(\mathrm{USD} \mathrm{m}^{-3}\right)$} \\
\hline P1 & P2 & P3 & P4 & P5 & P6 \\
\hline Cotton & 0.287 & 0.118 & 0.036 & 0.008 & 0.001 & 0.00001 \\
Wheat & 0.062 & 0.025 & 0.008 & 0.002 & 0.000 & 0.000 \\
Groundnut & 0.083 & 0.034 & 0.011 & 0.002 & 0.000 & 0.000 \\
Sorghum & 0.017 & 0.007 & 0.002 & 0.000 & 0.000 & 0.000 \\
\hline
\end{tabular}

where $R$ is the release at Merowe Dam.

\subsubsection{Continuity constraints}

Storage at each dam location can be calculated using simple water balance. The storage at a particular time step is the total water contained in the reservoir in the previous time step plus the water entering each dam minus what comes out of the reservoir through upstream flow (Eq. 8). The water entering is the upstream boundary flow or upstream total dam release ( $q_{1, \mathrm{~m}, \mathrm{y}}$ or $r_{1, \mathrm{~m}, \mathrm{y}}$, respectively); the water leaving each dam node is the current dam release, i.e., the irrigated water and water loss due to evaporation.

$$
\begin{aligned}
& \forall_{1, \mathrm{~m}, \mathrm{y}}, s_{1, \mathrm{~m}, \mathrm{y}}=q_{1, \mathrm{~m}, \mathrm{y}}+r_{(1-1), \mathrm{m}, \mathrm{y}}+s_{1,(\mathrm{~m}-1), \mathrm{y}} \\
& -r_{1, \mathrm{~m}, \mathrm{y}}-i_{1, \mathrm{~m}, \mathrm{y}}-e_{1, \mathrm{~m}, \mathrm{y}}
\end{aligned}
$$

$\mathrm{NB}: s_{1,(\mathrm{~m}-1), \mathrm{y}}$ is the storage from the previous time step. When $\mathrm{m}=1$, the model uses the storage from $s_{1,12,(\mathrm{y}-1)}$. Evaporation in $\mathrm{m}^{3} / \mathrm{m}^{2}$ (Ev) is estimated using the Thornthwaite equation (Thornthwaite, 1948); thus, the total evaporated volume is $e=\mathrm{Ev}$. Dam Surface Area. The storage at each time step must also be less than each dam's respective maximum volume (Vmax) (Eq. 9).

$s_{1, \mathrm{~m}, \mathrm{y}} \leq \mathrm{Vmax}$

Lastly, all the decision variables calculated by the optimization model must satisfy non-negativity constraints (Eq. 10):

$s_{1, \mathrm{~m}, \mathrm{y}}, \mathrm{rhe}_{1, \mathrm{~m}, \mathrm{y}}, i_{1, \mathrm{~m}, \mathrm{y}} \geq 0$.

\subsection{Model parameters}

\subsubsection{Marginal value of water for irrigation}

Deriving the net benefits due to agriculture requires an intimate knowledge of both foreign and domestic agricultural economic markets. Calculating prices of output commodities relative to input production costs for future scenarios would require accurate price prediction of a nonlinear, volatile market. Rather than attempting to analyze and project costs of agricultural inputs (e.g., water rates, fertilizer, land and labor) or to simplify tax rules and subsidies currently affecting agricultural prices in Sudan, we assign marginal water values for agriculture by assuming a horizontal demand curve for the marginal water values for each crop and that the average value of water equals the marginal value. The ratio of marginal water values for the crops was calculated using the producer price of the crop $\left(P_{\mathrm{c}}, \mathrm{FAO}, 2009\right)$, the yield $\left(Y_{\mathrm{c}}\right.$, Ghezae, 1998), and the crop water requirement (water, Plasquelle, 1990). To explore the sensitivities of the model, we perform simulations using six different sets of marginal water values, with each crop assigned its own value (P1P6; Table 3). These values chosen are illustrative and are intended to assess the sensitivity of the model, and are not meant to reflect the optimal estimate of current agricultural prices. Therefore, the marginal crop values act as weights within the objective function to develop a tradeoff between the various objectives, as described in Sect. 3. For comparison, previous studies within the region have assumed a horizontal demand curve with an assigned marginal water value of USD $0.05 \mathrm{~m}^{-3}$ for agriculture (Whittington et al., 2005; Arjoon et al., 2014).

\subsubsection{Discount rate $\left(D^{y}\right)$}

Economic analyses of large-scale development projects need to discount anticipated future benefits relative to near term costs and benefits forgone. Since the objective function and decision making in our model is solely based on economics, the discount rate can greatly influence the final value of the objective function of the model. To quantify this influence, we performed simulations in which discount rate was varied from 3 to $7 \%$, a range that has a considerable impact on the total value of the objective function, but not on the overall results. Discount rates may also affect the analysis of our deterministic hydro-economic model by front-loading demands. In this model, this phenomenon is minimized by treaty constraints that limit water allocation for irrigation (Eqs. 6 and 7). The same discount rate was applied to both objectives within the objective function. The results presented in Sect. 3 used a discount rate of $5 \%$ for all analyses.

\subsubsection{Simulations}

We apply SHOM to a set of hydrological and development scenarios to test sensitivities to changes in flow volume and timing in the Blue Nile as well as to investigate the influence that changing agricultural practices, electricity markets, and international agreements might have on optimal water allocations. A list of these scenarios is provided in Table 4.

First, we examine sensitivity to changes in Blue Nile hydrology. As noted above, there is significant uncertainty in projections of future precipitation patterns - and hence future river flows - in the Blue Nile basin. For this reason, we consider it important to test model sensitivity to substantial increases $(+20 \%)$ "high flows" and decreases $(-20 \%)$ "low flows" in river flow, which is within the range of predictions of state of the art global climate models for the first half of 
Table 4. Description of the simulations used in SHOM.

\begin{tabular}{ll}
\hline Simulations & Description \\
\hline High flows & $+20 \%$ observed \\
Low flows & $-20 \%$ observed \\
Smoothed flows & Three month averaged \\
Smooth2crop & Smooth Flow +2 cropping seasons \\
SmoothPower & Smooth Flow +0.04 cents $\mathrm{KWh}^{-1}$ power price \\
Smooth2cropNA & Smooth Flow +2 cropping seasons + removal of second 1959 agreement constraint \\
SmoothPower2crop & Smooth Flow +0.04 cents $\mathrm{KWh}^{-1}$ power price +2 cropping seasons \\
SmoothPower2cropNA & Smooth Flow +0.04 cents $\mathrm{KWh}^{-1}$ power price +2 cropping seasons \\
& + removal of second 1959 agreement constraint \\
\hline
\end{tabular}

the twenty-first century. These simulations are compared to an "observed flow" simulation based on historic flow rates.

In addition, we are interested in how the model responds to temporal smoothing of inflow from Ethiopia, which might result from the construction of one or more upstream dams. For this reason, we include a third flow scenario, "smoothed flows," in which the annual total flow is unchanged from present conditions but monthly flow values are averaged across 3 months, producing a smoothed hydrograph with less extreme wet season peaks and dry season troughs.

Changes in flows were restricted to the Blue Nile flows only; White Nile flows remained unchanged. This approach was adopted for multiple reasons. First, the White Nile originates in the Equatorial Lakes region, which is in a different climate zone. Thus, it is unclear that an increase in Blue Nile flows would translate into an increase in White Nile flows. Second, the White Nile passes through the Equatorial Lakes and Sudd wetland, so that its annual flow is more buffered than the Blue Nile. Lastly, the majority of the water in Egypt originates from the Blue Nile region, so changes in White Nile flow under climate change would not impact the main stem Nile as significantly as changes in the Blue Nile.

Next, we consider how changing agricultural management practices due to upstream development might alter optimal allocations under a smoothed flow regime. Expected upstream development will increase water availability during the dry months, which will incentivize farmers to change their agricultural practices. This has already been observed on the Atbara River, just north of the Blue Nile, where construction of a dam in Ethiopia has led Sudanese farmers to transition from a one cropping season to a multiple cropping season and to diversify crop types (personal communication, Professor Belay Simane, Addis Ababa University, 2014). For this reason, we have included simulations to the smooth flows that add a second cropping season (Table 4 simulation "Smooth2crop").

Third, we examine sensitivity to electricity prices. The construction of a large upstream structure like the GERD would produce a large amount of hydropower itself, and in a connected electricity market this would drive down the price of electricity. The GERD, for example, is expected to generate electricity that can be sold to Sudan at a reduced price, about 4 cents $\mathrm{KWh}^{-1}$ (Hai, 2013). To account for this dynamic in general terms, we include a model simulation ("SmoothPower") in which flow is smoothed and the price of electricity is cut by half from 8 to 4 cents $\mathrm{KWh}^{-1}$ (see Table 4). We also consider how this change in power price might interact with a change in cropping practices in simulation "SmoothPower2Crop."

Finally, we introduce simulations in which there is upstream flow control, the opportunity for double cropping, and a relaxation of the downstream constraint. This relaxation, which we call "No Agreement" (NA), removes the requirement that Sudan provide adequate flow to Egypt in dry years - i.e., our second "treaty" constraint from Sect. 2.1.3 (Eq. 7). These simulations were performed for both high and low electricity prices: "Smooth2CropNA" and "SmoothPower2CropNA." Removing the second constraint allows us to examine the impact that downstream delivery requirements have on Sudan's optimal water allocations while keeping the total water use relatively similar to the baseline simulations, which facilitates comparisons between simulations.

All simulations in the sensitivity analysis were run for 20 years. To generate hydrological inputs for these simulations, a 70 year record of monthly observed Blue Nile flows at Roseires was obtained from the Global Runoff Data Center (www.grdc.org). This record was randomly resampled to generate 100020 year time series of representative flow patterns. Interannual autocorrelation is insignificant (lag-1 autocorrelation is 0.165 ) for this hydrological time series data set; thus, the distortive effect of resampling is minimal. The mean flow for all 1000 bootstrapped time series were assembled and ranked, thus defining the 5 and $95 \%$ confidence levels of flows for the 20 year observed period. The model output was assessed using these confidence intervals. 

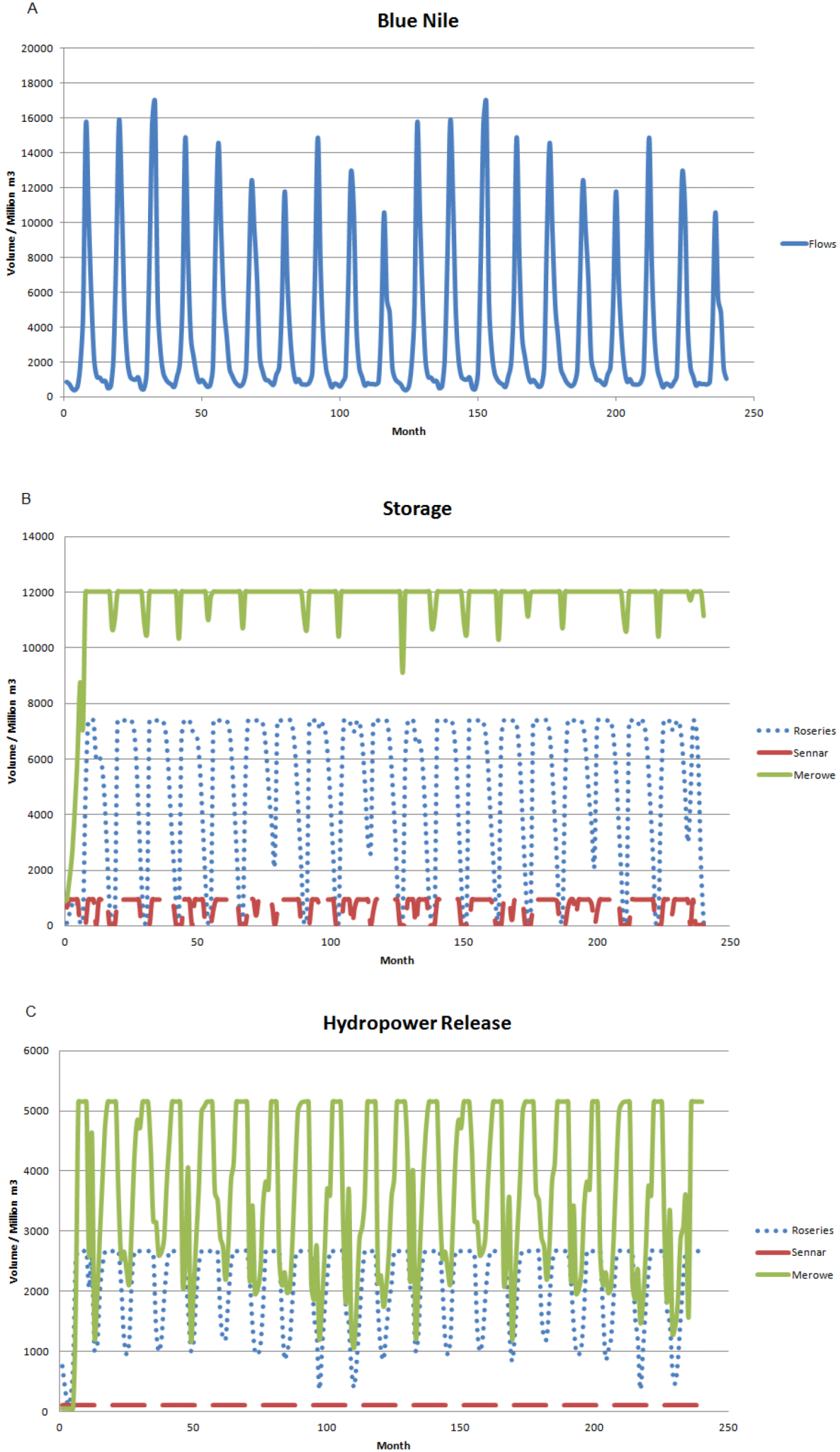

Figure 3. Annual cycle of (a) observed flow, (b) storage and (c) hydropower release at the three dams over the 20 year demonstration simulation. 


\section{Results and discussion}

\subsection{Model behavior}

To demonstrate general model behavior, we first examine a 20 year demonstration simulation that uses bootstrapped historical flows and the P5 set of marginal water values (see Table 3). Hydrologic fluxes and storages at the three dams in the simulation (Roseires, Sennar, and Merowe) and for major irrigation areas are shown in Figs. 3 and 4.

Figure 3a shows the observed 20 year flows for the Blue Nile at the Sudan-Ethiopia border. Fluctuations of flows are illustrative of the wet and dry seasonal pattern, and annual flows also vary significantly, from -26 to $26 \%$ of the mean. This record shows two distinct periods of below average annual flows (months 70-120 and 190-240). The dam storage and release values reflect a response by the model to these periods of interseasonal dryness and wetness. The smaller dams (Roseries and Sennar) are emptied and filled annually (Fig. 3b) with Merowe remaining relatively full year round in all years, with minor drops in its storage level during the dry months. Therefore, there is no significant connection between the hydropower releases at Merowe and interannual variability. There is a significant connection between dry periods and hydropower release at Roseries. This is illustrated by lower hydropower releases during the periods of dry annual flows than during the wet periods (Fig. 3c).

Figure 4 also shows results for the base case simulation, but as 20 year average seasonal cycles of storage, release, and withdrawals at each major dam and irrigation zone across the 1000 bootstrapped simulations. It is clear from Fig. 4a that the large reservoir at Merowe is relatively insensitive to seasonal variability and to climatic variability represented by bootstrapping. This offers a more robust view of the sensitivity of optimal reservoir operation and water withdrawals to season and to potential patterns of variability given historical conditions.

Figure 4a shows that the dams along the Blue Nile (Sennar and Roseires), in contrast, are significantly sensitive to seasonal and interannual variability: in the months preceding the wet season, both Sennar and Roseires are emptied and then refilled during the rainy season, while Merowe is able to remain relatively full year round maximizing hydropower generation. This is in small part a product of the fact that Blue Nile flows are more strongly seasonal than main stem flows, which are slightly moderated by inflow from the White Nile. But, the primary reason for the difference is the model's objective to maximize total benefit through the system. Maximizing hydropower output requires large hydropower release (Fig. 4b), and adequate head through the turbines (see the hydropower constraints section). Since Merowe is the largest hydroelectric facility, it is critical to hydropower optimization that it is active and that its reservoir is relatively full for as much of the year as possible. The model maximizes hydropower by maintaining Merowe at full capacity for most of the dry months at the expense of storage at Roseries and Sennar. Thus, Roseries is emptied between January and May and a relatively full dam is maintained at Merowe for most of the dry season, maximizing total hydropower production. Since the Blue Nile has highly seasonal flows and Roseires and Sennar are relatively small dams, this comes at the cost of seasonally reduced reservoir storage and hydropower potential at those dams. In Fig. 4a and b, the largest variability between simulations (biggest \pm bars) is observed during the months of emptying and filling (February-August), reflecting sensitivity to interannual climate variability.

Figure $4 \mathrm{c}$ shows total water withdrawal amounts during the cropping season upstream of Sennar Dam, which would include the Rahad, Suki and Upstream Sennar irrigation schemes, and upstream of Merowe Dam, which includes the Geziera and Downstream Sennar irrigation schemes. Since the larger schemes are situated upstream of Merowe and downstream of Sennar, the largest withdrawals are downstream of Sennar. There were four crops modeled with different cropping cycles that overlapped during the season (Table 1), so the total agricultural water requirement varied on a monthly basis. Withdrawals, however, were maintained at between 1 and 2.5 billion $\mathrm{m}^{3}$ on average from July to October and drop to zero during the non-cropping period.

Currently, the influence of agriculture on dam management is limited due to two factors. First, though the crop calendar is somewhat different for each of the four crops, there is only one cropping season, which approximately coincides with the wet months, so agricultural productivity peaks when the water supply via Blue Nile peak flows is plentiful (Fig. 4c) and the total annual withdrawals are limited by prevailing agricultural practices. Second, as shown in the tradeoff analysis below (Sect. 3.2), the 1959 Nile Waters Agreement constraints serve as a cap on water demands for scenarios with high marginal values of water for agriculture.

\subsection{Tradeoff analysis}

Understanding the tradeoff between hydropower and irrigation is central to understanding how the model allocates water to the different objectives. Figure 5 shows results of simulations for three of the marginal values (P2, P4 and P5) represented in Table 3. The agricultural benefit is removed from the objective function and phrased as a constraint, and thus a tradeoff curve can be constructed that illustrates the hydropower-agriculture relationship for each set of agricultural marginal water values. For the case with higher marginal value of water for agriculture (P2), the gradient of the tradeoff curve is low. Thus, the loss of one unit benefit of hydropower would result in a gain of more than one unit benefit of irrigation. In order to maximize total benefits, then, the model would allocate more and more water to agricultural production until it hits a constraint. For the case with a low marginal value of water for agriculture (P5), the opposite is true: the model prioritizes moving water through 

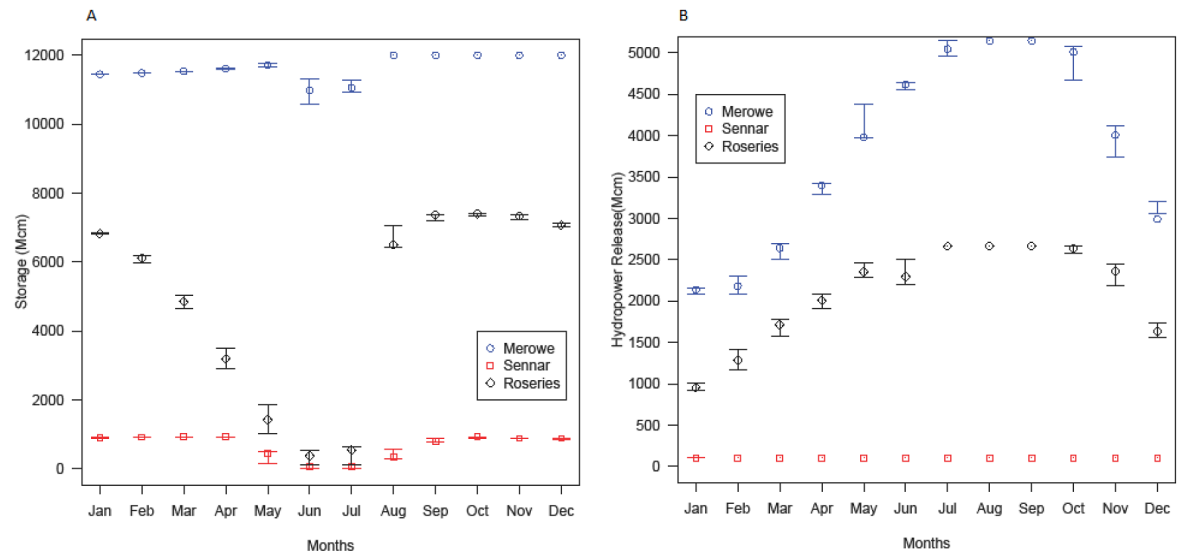

Jan Feb Mar Apr May Jun Jul Aug Sep Oct Nov Dec

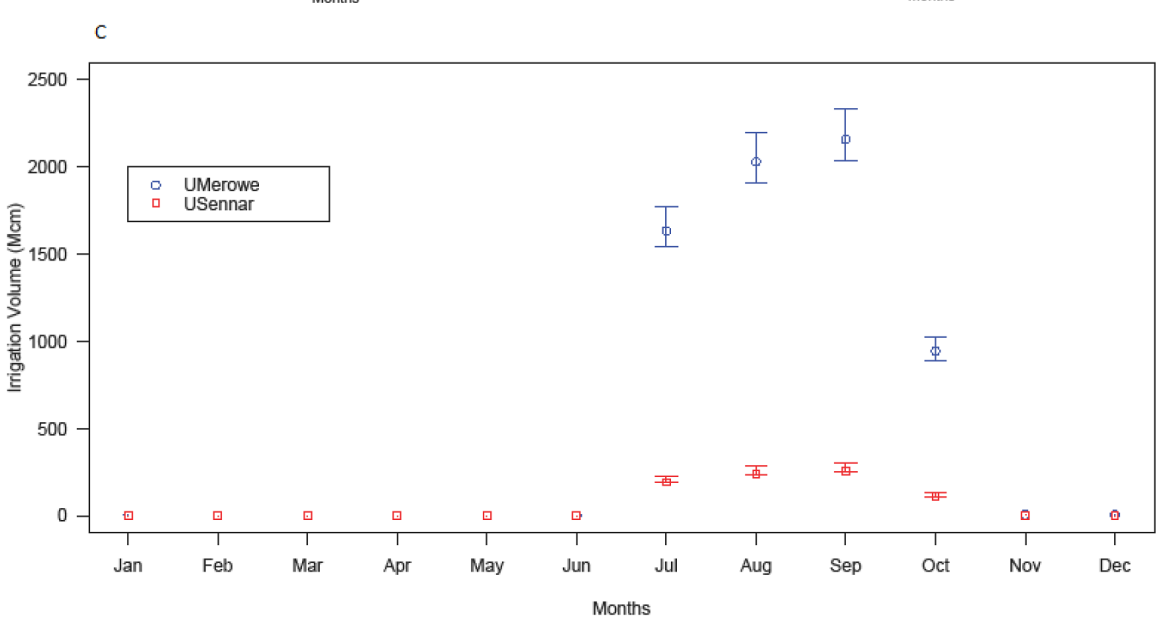

Figure 4. Annual cycle of (a) reservoir storage and (b) hydropower release at the three dams, and (c) irrigation withdrawals upstream of Sennar and upstream of Merowe in the base case simulation of bootstrapped historical flows and marginal values P4. Data points are the mean average value over the 20 year simulation and error bars represent the difference in output between the 5 and $95 \%$ confidence interval bootstrapped flow.

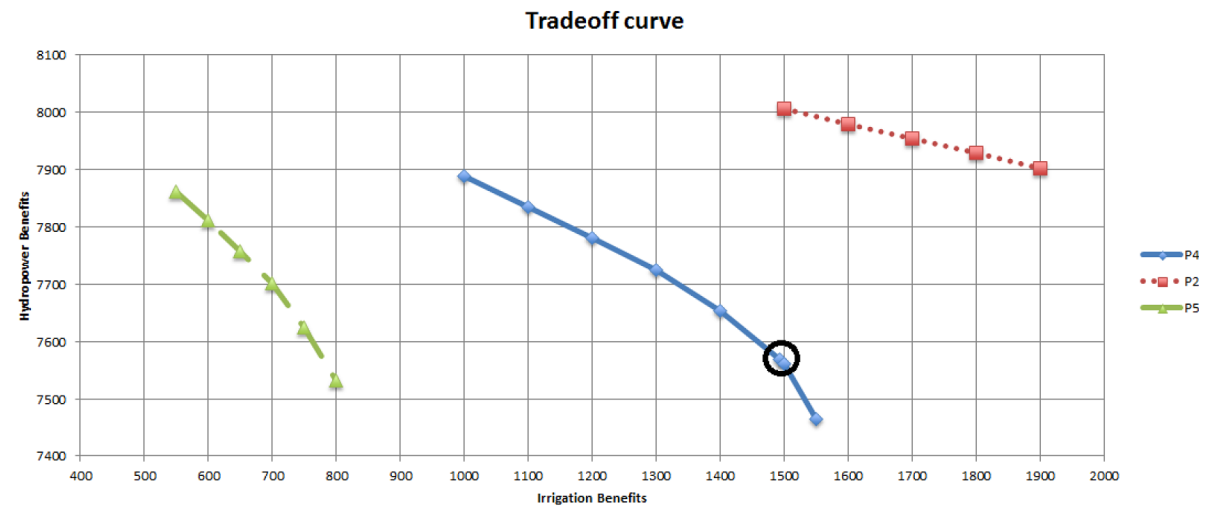

Figure 5. SHOM hydropower vs. irrigation benefit tradeoff curves for three different water values (P2, P4 and P5).

the turbines at the expense of agriculture. For intermediate marginal water values $(\mathrm{P} 4)$, there is an inflection point at which the gradient is equal to 1.0 (circled point in Fig. 5). To the left of the point, the gradient is less than 1.0, which would cause the model to shift towards agriculture, and to the right it is greater than 1.0, pushing the model back towards hydropower. Thus, the inflection point is the optimum balance between agriculture and hydropower for that marginal value of water under given simulation conditions. 


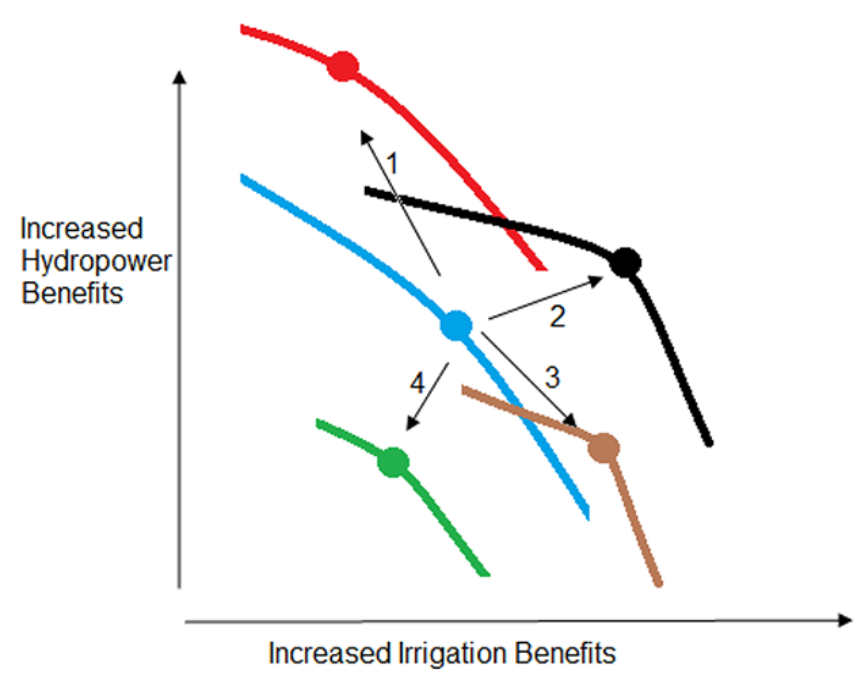

Figure 6. Schematic of the four possible ways in which changing conditions can shift the optimum model solution from a baseline set of solutions represented by the blue curve. Arrow 1 (shift to the red curve) depicts a win-loss tradeoff where a loss in irrigation benefits is offset by an increase in hydropower benefits. Arrow 2 (shift to the black curve) depicts a win-win outcome, with a gain in both hydropower and irrigation. Similarly, arrows 3 and 4 can be characterized as loss-win and loss-loss, respectively.

The implications of the optimal inflection point for total benefits are illustrated schematically in Fig. 6 . The blue line in Fig. 6 represents a base case scenario with an optimum division between irrigation and hydropower indicated by the inflection point at a gradient equal to 1 . The other lines are representative of scenarios in which changing conditions altered flow regime, market modifications, policy decisions, or other external factors - shift the optimum in a manner that can change both the total value realized from the system and the division between irrigation and hydropower. A movement up and to the right on the chart is a win-win condition for Sudan in which both irrigation and hydropower benefits increase, while a move down and to the left is a lose-lose scenario. Movement up and to the left and down and to the right are tradeoff scenarios in which hydropower benefit increases to the detriment of irrigation and vice versa. The interpretation of these "wins" and "losses" would, of course, differ for other stakeholders. Egypt might view movement to the right on the chart - increasing irrigation withdrawals - as a potential threat to water resources in the absence of increased Nile river flow or the counterbalancing shared benefits.

With this framework in mind, we next consider simulations for one set of marginal water values (P4). These simulations allow us to ascertain the changing nature of the tradeoff curves for changes in mean flow consistent with the range of predicted climate change and for changes in flow timing representative of flow regulation from upstream development. P4 is used because it represents an intermediate set of prof- itability values; P3-P1 have high irrigation profitability and are limited by the 1959 constraints, while P5 and P6 push simulations strongly towards hydropower. Figure 7 shows the results of these simulations, with inflection points indicated as circles around the point at which the gradient crosses through 1.0. These circled data points are the optimal values for each scenario at which the model would converge for the given hydrologic inputs and parameter values.

The relative position of these inflection points lies at the core of optimization-based hydro-economic analysis. When a change in hydrology (e.g., "high flow" vs. "observed flow") causes the inflection point to move to the right on the chart it suggests that this hydrologic change will push Sudan towards more irrigation. Similarly, if the inflection point moves up on the chart it suggests that the hydrologic change is pushing Sudan towards hydropower. These dynamics matter enormously for studies of how climate change or upstream development is likely to impact Sudan's water resource decision making. Movement that is up and to the left or down and to the right is particularly interesting, as it suggests that $\mathrm{Su}-$ dan's optimal development strategy involves a shift between hydropower and irrigation. In more general terms, a hydrologic shift that moves the optimal point up and to the left in Fig. 6 could be thought of as a change that pushes Sudan towards a hydropower development pathway, while a shift that moves the point down and to the right pushes Sudan towards an irrigation development pathway relative to baseline simulation conditions.

Model sensitivity to reduced flow $(-20 \%)$ is consistent with expectation. For the P4 water value set, this low flow scenario results in a decrease in benefits from both irrigation and hydropower production (triangles and dashed line in Fig. 7). Conversely, an increased flow $(+20 \%)$ increases both agricultural production and hydropower production (squares and dotted line in Fig. 7). Lastly, the smoothed flows show an increase in hydropower and almost no change in irrigation benefits. Stabilized flows increase water availability during the dry season and at the tail ends of the wet season, and thus there is more water available throughout the year for hydropower, increasing its benefits (crosses and solid line in Fig. 7).

Next, the sensitivity to agricultural value was analyzed by varying marginal value of water in agriculture (P1-P6). Figure 8 shows the tradeoff curve of Pareto optimal values of hydropower and irrigation benefits for P1-P6 (see Table 3). A solution point is Pareto optimal if there is no other feasible point that improves at least one objective function without exacerbating another objective function. As described above, a higher marginal value for agriculture assigns greater weight to agricultural production, which could be interpreted as a higher agricultural profit margin. First, we note that, for all scenarios in Fig. 8, the tradeoff curves flatten out at very high values of irrigation benefit. This flattening reflects the fact that at high marginal values the agricultural benefits are limited by the 1959 Nile Waters Agreement constraints. 


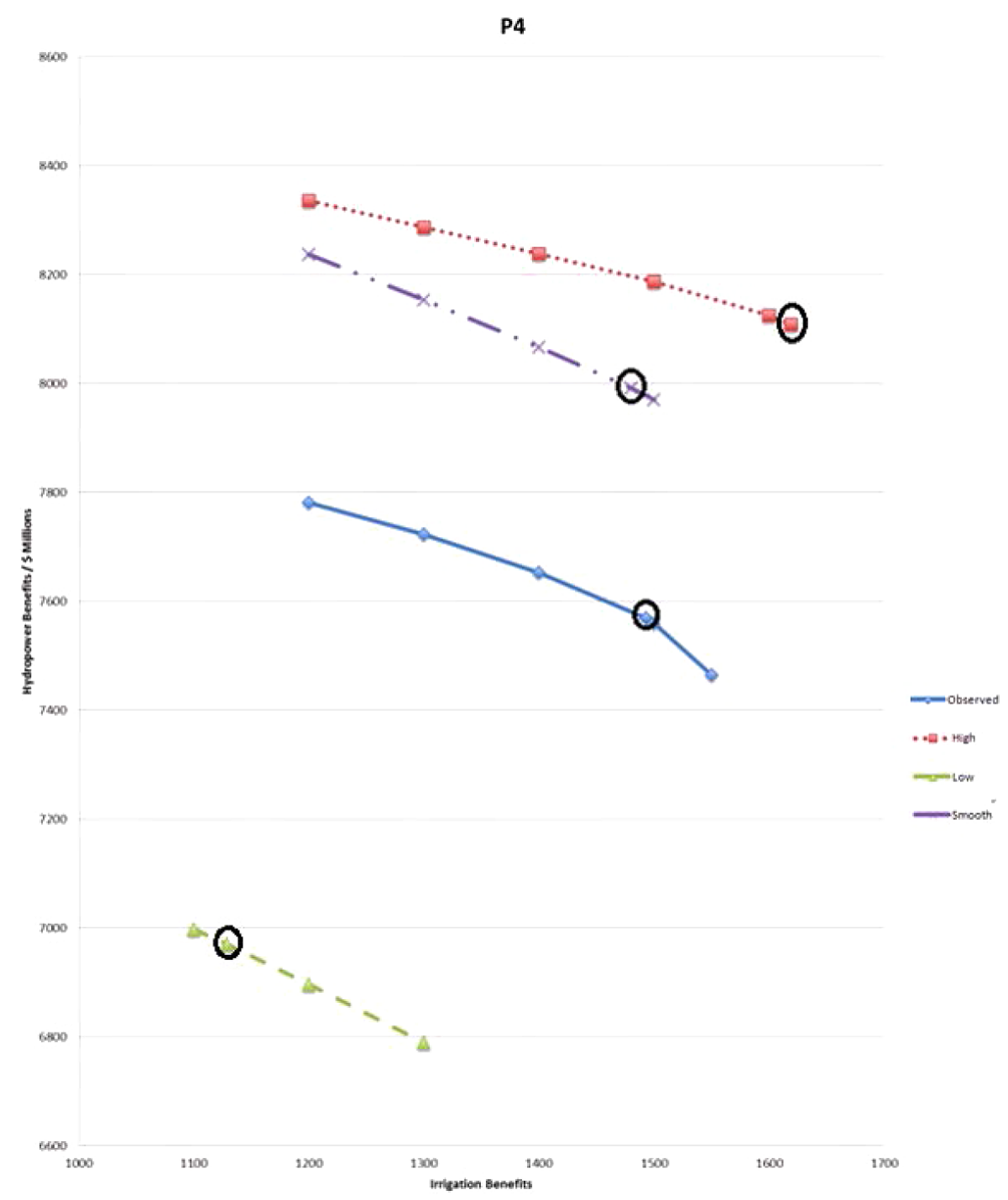

Figure 7. Results of SHOM simulations in which the agricultural benefits are phrased as constraints, and the hydropower benefits are calculated for a specific agricultural benefit. The circles highlight the optimal values for each scenario.

The tradeoff curve approaches horizontal because the same amount of water is allowed to pass downstream through the turbines at Merowe, while the calculated irrigation benefit per unit water continues to increase when marginal value is set to higher values.

Perhaps more interestingly, Fig. 8 can also be used to study how the marginal value of agricultural water affects the impact that a change in flow regime has on optimal water allocation. For the smoothed flow (upstream development), all marginal water value sets (P1-P6) show no significant increase/decrease in agriculture benefits, due in part to withdrawal restrictions imposed by the 1959 treaty and, perhaps, in part to the absence of a second cropping season in these simulations. All the P1-P6 marginal values, however, provide a win for Sudan: greater hydropower benefits. In other words, smoothed flows allow for more effective use of existing hydropower infrastructure.

The SmoothPower simulation (smoothed flow with a drop in the price of power) shows a policy shift from a hydropower-centric solution to a policy that increases agricultural production. Interestingly, this shift is relatively modest in all cases and is extremely small for simulations with high agricultural marginal water values (P1-P3). This in large part reflects the limitation on Sudan's annual water withdrawals imposed by the model's downstream constraints, which guarantee flow to Egypt. For P1-P3, the Smooth Flow simulation already runs up against these constraints, preventing larger shifts to irrigation in SmoothPower.

We note that all of these results, including the shift to agriculture in SmoothPower, are for existing cropping prac- 


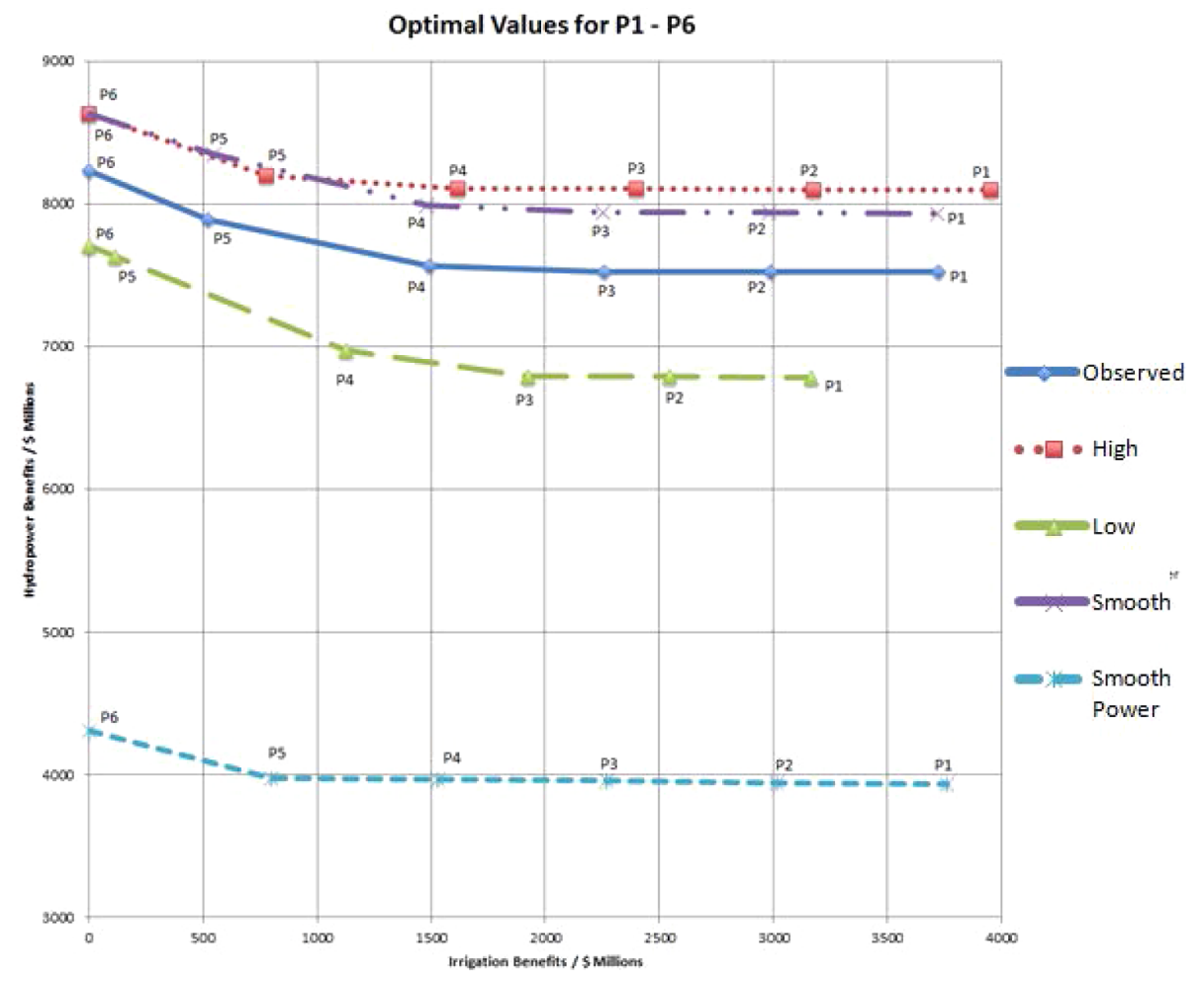

Figure 8. Hydropower vs. irrigation benefits in SHOM simulations. Points represent Pareto optima values for water value sets P1-P6.

tices. Figure 9 considers a shift in management practices and introduces a second cropping season to the smoothed flow. An additional cropping season shows increases in irrigation benefits particularly if agricultural marginal water values are high (P1-P3). Smooth2crop in Fig. 9 introduces a second crop season to the smoothed flow, and SmoothPower2crop includes this double cropping and an estimate of less expensive power due to upstream production sold to Sudan. The modest increases in irrigation benefits for these flows, particularly in scenarios of high irrigation profitability, illustrate Sudan's limitation due to the constraints in the model representative of the 1959 agreement. The second constraint guarantees at least 3 times more water passing Merowe downstream into Egypt than it allows for irrigation at upstream schemes, thereby forcing Sudan toward a hydropower path and limiting its irrigation potential (see irrigation constraints in Sect. 2.1.3, Eq. 7).

To test for the restrictive nature of the 1959 agreement in our simulations, we have included two additional runs that remove the second constraint of the 1959 agreement (Smooth2cropNA and SmoothPower2cropNA) but maintain Sudan's long term average water use at 14.5 billion $\mathrm{m}^{3}$. SmoothPower2cropNA includes the reduction in power price due to upstream control and the removal of the second 1959 constraint. Both runs show a significant increase in irrigation benefits for cases P1-P3 (Fig. 9).

\section{Conclusions}

This paper introduces a hydro-economic model for Sudan (SHOM) that considers hydropower and irrigation benefits under conditions of existing infrastructure and practices. SHOM includes a nonlinear multi-objective optimization routine that allows us to study interactions between component objectives under a range of flow scenarios and valuation of agricultural returns. A number of our modeling results confirm or complement previous hydro-economic analyses for example, the fact that upstream regulation can provide benefits to downstream riparians. Ajoon et al. (2014), for example, show that including the GERD in a SDDP hydroeconomic model resulted in an increase in hydropower generation in Sudan and Egypt. Other results are intuitive, such as the fact that under reduced flows there is a decline in hydropower and irrigation benefits. However, even in this simple sensitivity test the model returns some non-obvious results. While one might expect that smoothing the Blue Nile hydrograph through upstream regulation would inevitably lead to increased irrigation withdrawals, we find that doing so is only beneficial under select combinations of marginal values of water and if the upstream facility results in a drop in the price of electricity in Sudan. Otherwise, the optimal development path is to increase hydropower production.

Another interesting result is the restrictive nature of the downstream flow constraint. The more that economic con- 


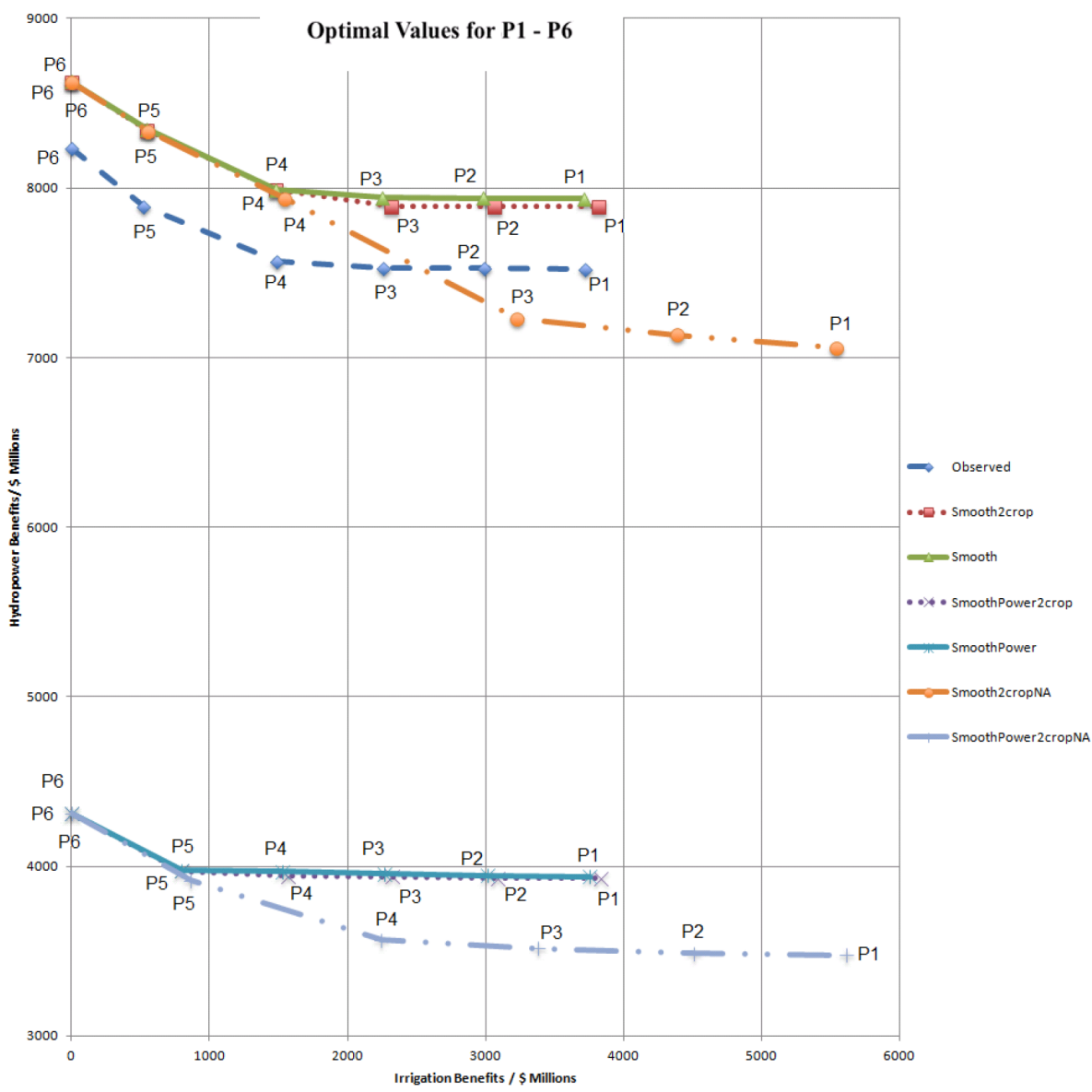

Figure 9. Hydropower vs. irrigation benefits illustrating adaptive management practices. Points represent Pareto optima values for water value sets P1-P6.

siderations (lowering of power prices and changes in agricultural practices) push Sudan towards irrigation, the more expensive these constraints - i.e., the restrictions imposed by a water sharing agreement - become to the country. The current requirement to deliver adequate flows to Egypt is not a severe constraint as long as agriculture is economically inefficient, irrigation is hampered by siltation and seasonal flow variability, and hydropower is an economic driver to send water downstream. But, if these realities are shifted by an upstream facility that regulates flow, reduces sediment load, and provides inexpensive electricity, the treaty-enforced cap on water use will quickly become a constraint on Sudan's optimal hydro-development options.

The modeling results presented in this study contribute to current understanding of Nile hydro-economics by presenting a focused analysis of Sudanese options, performed with a multi-objective optimization model capable of capturing nonlinear interactions. There are, however, a number of important limitations that need to be addressed in future model development. First, the model does not include knowledge of current dam operating procedures, or of stage-volume relationships for proposed dams (GERD), or of existing dams in recent years. Second, the model does not include the effects of siltation. A dam that controls siltation would affect the objective function by easing dam operation and significantly reducing dredging costs for canals that feed irrigation schemes. At the same time, reduced silt load would increase the need for fertilizer in downstream agricultural lands that currently benefit from natural nutrient input from silt-laden waters. Third, limitations in current agricultural and economic data make it difficult to estimate total agricultural benefits, so the marginal value of agricultural water essentially functions as a tuning parameter in SHOM that allows us to study general sensitivity to the value of agriculture. This could certainly be improved with access to more reliable and recent agricultural data, though the perceived value of agriculture and the support of this value through land and economic policies are always difficult to quantify.

The scope of SHOM is also a matter of ongoing evaluation. In focusing on hydropower and irrigation we adopt the framework of many earlier hydro-economic optimization models in the Nile and elsewhere. We recognize, however, that climate change and river development can have a broad range of impacts, many of which are difficult to quan- 
tify. These include ecological impacts, effects on fisheries, and burden placed on particular populations living within the basin. These important considerations must be accounted for in any application of hydro-economic analysis to development decision making, and it would be valuable to find ways to broaden Nile basin hydro-economic models to include a more diverse array of processes and outcome variables. Lastly, we recognize that our use of a deterministic model presents a highly idealized scenario of a decision maker with perfect foresight. Deterministic models do not account for the uncertainties in some of the input parameters; therefore, the results and decisions presented in this paper will produce benefits that are higher than any real-world scenario.

Future operation of SHOM may be within a value of an information framework that aims to assess operational seasonal forecasts. A more in-depth study of the value of information of seasonal forecasts will require the conversion of SHOM from a deterministic model to a stochastic model in order to adjust to the stochastic nature of forecasts. In addition, we would add that our analysis was performed for a portion of the Blue Nile as well as the downstream main Nile stem within Sudan. Future development of the model should incorporate other major tributaries such as the White Nile and the Atbara. Inclusion of other Nile tributaries and their infrastructure in the model will present a more holistic approach to analyzing Sudan's water resource decision making.
The Nile River is a finite water resource shared by a number of emerging economies, and the long-standing tensions regarding its equitable use are only increasing as demand for food, water, and electricity rise across the region. On account of both history (i.e., the 1959 Nile Waters Agreement) and geography, the Republic of Sudan is a particularly critical player in determining the future of Nile development and related hydro-economic development decisions in neighboring countries. The effect of climate change and upstream development, in turn, will be critically important in determining Sudan's long term optimal development path and associated policy decisions. Here, we present a first analysis targeted specifically at Sudan's optimal irrigation and hydropower development options under scenarios of changing Nile flows and upstream development. Results reinforce the understanding that Sudan has the potential to weigh in heavily on matters of regional water and food security depending on how it chooses to make use of the Blue Nile and main stem Nile as it flows through its territory. Further research is required to understand how these choices are affected by additional development, trade, and policy decisions within the basin, and how Sudan's own infrastructure and agricultural practices might evolve to optimize returns under evolving climatic and economic conditions. 


\section{Appendix A}

\section{A1 SHOM model}

\section{Objective function}

Objective $=\max \sum_{\mathrm{m}, \mathrm{y}}\left(D^{y} \cdot \mathrm{bi}_{\mathrm{m}, \mathrm{y}}+D^{y} \cdot \mathrm{bh}_{\mathrm{m}, \mathrm{y}}\right)$

\section{A2 Constraints}

\section{Hydropower}

$\forall_{1, \mathrm{~m}, \mathrm{y}}, \mathrm{KWH}_{1, \mathrm{~m}, \mathrm{y}}=c \cdot \mathrm{effh} \cdot n \cdot \mathrm{rhe}_{\mathrm{l}, \mathrm{m}, \mathrm{y}} h_{1, \mathrm{~m}, \mathrm{y}}$

$\mathrm{bh}_{\mathrm{m}, \mathrm{y}}=\sum_{1}\left(P \cdot \mathrm{KWH}_{1, \mathrm{~m}, \mathrm{y}}\right)$

$\forall_{1, \mathrm{~m}, \mathrm{y}}, r_{1, \mathrm{~m}, \mathrm{y}}=\mathrm{rhe}_{1, \mathrm{~m}, \mathrm{y}}+\mathrm{nhe}_{\mathrm{l}, \mathrm{m}, \mathrm{y}}$

$r_{1, \mathrm{~m}, \mathrm{y}}=$ total release, rhe $_{1, \mathrm{~m}, \mathrm{y}}=$ hydropower release, nhe $1, \mathrm{~m}, \mathrm{y}=$ non-hydropower release

$\forall_{1, \mathrm{~m}, \mathrm{y}}, \mathrm{rhe}_{1, \mathrm{~m}, \mathrm{y}} \leq Q_{\mathrm{dc}}$,

\section{Irrigation}

$$
\begin{aligned}
& i_{1, \mathrm{~m}, \mathrm{y}}=\sum_{c}\left(\text { effi }_{c} \cdot \text { Water }_{c, 1, \mathrm{~m}, \mathrm{y}} \cdot \text { Area }_{c, 1, \mathrm{~m}, \mathrm{y}}\right) \\
& \mathrm{bi}_{\mathrm{m}, \mathrm{y}}=\sum_{c, 1}\left(\text { effi }_{c} \cdot v_{\mathrm{c}} \cdot \text { Water }_{c, 1, \mathrm{~m}, \mathrm{y}} \cdot \text { Area }_{c, 1, \mathrm{~m}, \mathrm{y}}\right) \\
& \sum_{1, \mathrm{~m}, \mathrm{y}}\left(i_{1, \mathrm{~m}, \mathrm{y}}\right)+\sum_{1, \mathrm{~m}, \mathrm{y}}\left(e_{1, \mathrm{~m}, \mathrm{y}}\right) \leq Y \cdot 14.5 \text { billion }^{3} \\
& \sum_{1, \mathrm{~m}}\left(i_{1, \mathrm{~m}, \mathrm{y}}\right)+\sum_{1, \mathrm{~m}}\left(e_{1, \mathrm{~m}, \mathrm{y}}\right) \leq 0.28 \cdot \sum_{\mathrm{m}}\left(R_{\mathrm{y}}\right) \\
& \sum_{c, 1} \text { Area }_{c, 1, \mathrm{~m}, \mathrm{y}} \leq 1.4 \text { million ha }
\end{aligned}
$$

\section{Continuity}

$$
\forall_{1, \mathrm{~m}, \mathrm{y}}, s_{1, \mathrm{~m}, \mathrm{y}}=q_{1, \mathrm{~m}, \mathrm{y}}+r_{(1-1), \mathrm{m}, \mathrm{y}}+s_{1,(\mathrm{~m}-1), \mathrm{y}}
$$

$-r_{1, \mathrm{~m}, \mathrm{y}}-i_{1, \mathrm{~m}, \mathrm{y}}-e_{1, \mathrm{~m}, \mathrm{y}}$

$s_{1, \mathrm{~m}, \mathrm{y}} \leq \mathrm{Vmax}$

Non-negativity constraints :

$s_{1, \mathrm{~m}, \mathrm{y}}, \mathrm{rhe}_{1, \mathrm{~m}, \mathrm{y}}, \mathrm{nhe}_{1, \mathrm{~m}, \mathrm{y}}, r_{1, \mathrm{~m}, \mathrm{y}}, i_{1, \mathrm{~m}, \mathrm{y}}, \operatorname{Area}_{c, 1, \mathrm{~m}, \mathrm{y}} \geq 0$

where $Q_{\mathrm{dc}}$ is the flow capacity through the turbines. 
Acknowledgements. This research was supported in part by the Environment, Energy, Sustainability and Health Institute (E $\left.{ }^{2} \mathrm{SHI}\right) \mathrm{Fel}-$ lowship and NASA applied science program grant NNX09AT61G.

Data are available at the Global Runoff Data Center (GRDC) GRDC Station no. 16663800 and NOAA National Climate Data Center (NCDC) Global Historical Climatology Network-Monthly (GHCN-M) temperature data set station Wad Medina no. 62751 in ghcnm.tavg.v3.qcu v3.2.2.20140804, WMO station code 62751 . (http://climexp.knmi.nl), as well as the Food and Agricultural (FAO) data set (FAOSTAT; http://faostat.fao.org/).

Edited by: G. Characklis

\section{References}

Arjoon, D., Mohamed Y., Goor Q., and Tilmant A. : Hydroeconomic risk assessment in the eastern Nile River basin, Water Resour. Econom., 8, 16-31, 2014.

Awulachew, S., Rebelo, L., and Molden, D.: The Nile Basin: tapping the unmet agricultural potential of Nile waters, Water Int., 35, 623-654, 2010.

Bernal, V.: Colonial moral economy and the discipline of development: the Gezira scheme and "modern" Sudan, Cult. Anthropol., 12, 447-479, 1997.

Beyene, T., Lettenmaier, D., and Kabat, P.: Hydrologic impacts of climate change on the Nile River Basin: implications of the 2007 IPCC scenarios, Clim. Change, 100, 433-461, 2010.

Bhattacharjee, P. and Zaitchik, B.: Perspectives on CMIP5 model performance in the Nile River headwaters region, Int. J. Climatol., 2015.

Blackmore, D. and Whittington, D.: Opportunities for cooperative water resources development on the eastern Nile: risks and rewards, Report to the Eastern Nile Council of Ministers, Nile Basin Initiative, Entebbe, 2008.

Block, P. and Strzepek, K.: Economic analysis of large-scale upstream river basin development on the Blue Nile in Ethiopia considering transient conditions, climate variability, and climate change, J. Water Res. Pl.-ASCE, 136, 156-166, 2010.

Block, P. and Strzepek, K.: Power ahead: meeting Ethiopia's energy needs under a changing climate review of development, Economics, 16, 476-488, 2012.

Block, P., Assis Souza Filho, F., Sun, L., and Kwon, H.: A streamflow forecasting framework using multiple climate and hydrological models, J. Am. Water Resour. Assoc., 45, 828-843, 2009.

Bureau of Reclamation, US Department of Interior: Land and Water Resources of the Blue Nile Basin: Ethiopia, Main Report and Appendices I-V, Government Printing Office, Washington DC, 1964.

Cascao, A.: Ethiopia - challenges to Egyptian hegemony in the Nile Basin, Water Pol., 10, 13-28, 2008.

Chesworth, P. M., Howell, P. P., and Allan, J. A.: The History of Water Use in Sudan and Egypt in the Nile, Resource Evaluation, Resource Management, Hydropolitics and Legal Issues, Centre of Near and Middle Eastern Studies, 40-58, 1990.

Cohon, J.: Multiobjective Programming and Planning, Dover Publications, Mineola, NY, 2003.
Conway, D.: From headwater tributaries to international river: observing and adapting to climate variability and change in the Nile basin, Global Environ. Change, 15, 99-114, 2005.

Drud, A. S.: CONOPT - a large scale GRG code, ORSA J. Computing, 6, 207-216, 1992.

Elamin, A., Saeed, A., and Boush, A.: Water Use efficiencies of Gezira, Rahad and New Halfa irrigated schemes under Sudan dryland condition, Sudan J. Des. Res. 3, 62-72, 2011.

Elshamy, M. E., Seierstad, I. A., and Sorteberg, A.: Impacts of climate change on Blue Nile flows using bias-corrected GCM scenarios, Hydrol. Earth Syst. Sci., 13, 551-565, doi:10.5194/hess13-551-2009, 2009.

Food and Agricultural Organization: FAOSTAT, available at: http: //faostat.fao.org/site/703/default.aspx\#ancor (last access: August 2013), 2009.

Gamal, K. A. E. M.: Impact of Policy and Institutional Changes on Livelihood of Farmers in Gezira Scheme of Sudan, M.S. Thesis, University of Gezira, Sudan, 2009.

Gebreluel, G.: Ethiopia's Grand Renaissance Dam: ending Africa's oldest geopolitical rivalry?, Wash. Quart., 37, 25-37, 2014.

Georgakakos, A.: New method for the real-time operation of reservoir systems, Water Resour. Res., 23, 1376-1390, 1987.

Georgakakos, A.: Extended linear quadratic gaussian control: further extensions, Water Resour. Res., 25, 191-201, 1989.

Georgakakos, A.: Topics on System Analysis and Integrated Water Resources Management, chap. 6, edited by: Castelletti, A. and Soncini-Sessa, R., Elsevier, Amsterdam, 2007.

Ghezae, N.: Irrigation Water Management. A Performance Study of the Rahad Scheme in Sudan, 1977-1996, PhD thesis, Uppsala University Library, Uppsala, Sweden, 1998.

Gleick, P.: Methods for evaluating the regional hydrologic impacts of global climate changes, J. Hydrol., 88, 97-116, 1986.

Goor, Q., Kelman, R., and Tilmant, A.: Optimal multipurposemultireservoir operation model with variable productivity of hydropower plants, J. Water Res. Pl.-ASCE, 137, 258-267, 2010.

Guariso, G. and Whittington, D.: Implications of Ethiopian water development for Egypt and Sudan, Int. J. Water Resour. D, 3, 105-114, 1987.

Hai, H.: Sudan, Ethiopia, Close Relations in All Fields, Sudan Vision, available at: http://news.sudanvisiondaily.com/details. html?rsnpid=_229800 (last access: 10 January 2015), 2013.

Hammond, M.: The Grand Ethiopian Renaissance Dan and the Blue Nile: Implications for transboundary water governance, GWF Discussion Paper 1307, Global Water Forum, Canberra, Australia, available at: http://www.globalwaterforum.org/2013/02/18/the- ?grand-? ethiopian-?renaissance-?dam-?and-?the-?blue-?nile-? implications-?for-?transboundary-?water-?governance/ (last access: 4 August 2014), 2013.

Harou, J., Pulido-Velazquez, M., Rosenberg, D., MedellínAzuara, J., Lund, J., and Howitt, R.: Hydro-economic models: concepts, design, applications, and future prospects, J. Hydrol., 375, 627-643, 2009.

Hussien, H.: Egypt and Ethiopia Spar Over the Nile, Opinion Piece, Aljazeera America, available at: http://america.aljazeera.com/ opinions/2014/2/egypt-disputes-ethiopiarenaissancedam.html (last access: 4 August 2014), 2014.

Igunza, E.: Will Ethiopia's Grand Rennaissance Dam Dry the Nile in Egypt, British Broadcasting Corporation, available at: http: 
//www.bbc.com/news/world-africa-26679225, last access: $4 \mathrm{Au}-$ gust 2014.

Knott, D. and Hewett, R.: Water resources planning in the Sudan, in: The Nile, Sharing a Scarce Resource, A Historical and Technical Review of Water Management and of Economic and Legal Issues, edited by: Howell, P. P. and Allan, J. A., Cambridge University Press, Cambridge, 205-216, 1994.

Loucks, D. P., Stedinger, J. R., and Douglas, H.: Water Resource Systems Planning and Analysis, Prentice-Hall, Englewood Cliffs, NJ, 1981.

McCartney, M and Girma, M.: Evaluating the downstream implications of planned water resource development in the Ethiopian portion of the Blue Nile River. Water Int., 37, 362-379, 2012.

McCartney, M., Ibrahim, Y. A., Sileshi, Y., and Awulachew, S. B.: Application of the Water Evaluation and Planning (WEAP) Model to simulate current and future water demand in the Blue Nile, in: Improved water and land management in the Ethiopian highlands: its impact on downstream stakeholders dependent on the Blue Nile, Intermediate Results Dissemination Workshop held at the International Livestock Research Institute (ILRI), Addis Ababa, Ethiopia, 5-6 February 2009, edited by: Awulachew, S. B., Erkossa, T., Smakhtin, V., and Fernando, A., International Water Management Institute, Colombo, Sri Lanka, 78, 2009.

Nawaz, R., Bellerby, T., Sayed, M., and Elshamy, M.: Blue Nile runoff sensitivity to climate change, Open Hydrol. J., 4, 137$151,2010$.

Plusquellec, H.: The Gezira Irrigation Scheme in Sudan, Objectives, Design, and Performance, World Bank, Technical Paper 120, Washington DC, 1990.

Soliman, E., Sayed, M., and Jeuland, M.: Impact assessment of future climate change for the Blue Nile basin, using a RCM nested in a GCM, Nile Basin Water Eng. Sci. Magazine, 2, 15-30, 2009.

Swain, A.: Ethiopia, the Sudan, and Egypt: the Nile River dispute, J. Mod. Afr. Stud., 35, 675-694, 1997.
Taye, M. T., Ntegeka, V., Ogiramoi, N. P., and Willems, P.: Assessment of climate change impact on hydrological extremes in two source regions of the Nile River Basin, Hydrol. Earth Syst. Sci., 15, 209-222, doi:10.5194/hess-15-209-2011, 2011.

Taylor, K., Stoffer, R., and Meehl, G.: An overview of CMIP5 and the experiment design, B. Am. Meteorol. Soc., 93, 485-498, 2012.

Teodoru, C., Wüest, A., and Wehrli, B.: Independent review of the environmental impact assessment for the Merowe Dam project (Nile River, Sudan), Eawag aquatic research, Kastanienbaum, Switzerland, 2006.

Thornthwaite, C. W.: An approach toward a rational classification of climate, Geogr. Rev., 38, 55-94, 1948.

United Arab Republic and Sudan Agreement (With Annexes) For The Full Utilization of the Nile Waters, signed at Cairo on 8 November 1959, in force: 12 December 1959, 6519 U.N.T.S., 63 , available at: http://www.internationalwaterlaw.org/documents/ regionaldocs/uar_sudan.html, last access: 10 August 2014.

Waterbury, J. and Whittington, D.: Playing chicken on the Nile?, the implications of microdam development in the ethiopian highlands and Egypt's New Valley Project, Nat. Resour. Forum, 22, 155-163, 1998.

Whittington, D.: Visions of Nile basin development, Water Pol., 6, $1-24,2004$.

Whittington, D., Wu, X., and Sadoff, C.: Water resources management in the Nile basin: the economic value of cooperation, Water Pol., 7, 227-252, 2005.

Yao, H. and Georgakakos, A. P.: Nile Decision Support Tool River Simulation and Management, Georgia Water Resources Institute, Georgia Tech, Atlanta, USA, 2003.

Yates, D. and Strzepek, K.: Modeling the Nile basin under climate change, J. Hydrol. Eng., 3, 98-108, 1998. 